\title{
Dime qué comes y te diré quién eres. Vida cotidiana, comidas e inmigración en el cine español
}

Tell Me What You Eat and I Will Tell You What You Are. Everyday Life, Food and Immigration in Spanish Cinema

\author{
Julieta Zarco \\ Università Ca' Foscari Venezia \\ julieta.zarco@unive.it
}

Durante las últimas décadas, la inmigración hacia los países del sur de Europa se ha convertido en una cuestión cotidiana. En el caso de España, estudios recientes señalan que el flujo inmigratorio ha crecido muy rápidamente, cambiando su tradición de país emisor a país de receptor de inmigrantes. Este artículo persigue un doble objetivo, por un lado analizar cómo el cine español representa la vida cotidiana (Lefevbre, 1971; De Certau, 1999; Perec, 1973 y Juan, 2008) de los inmigrantes que llegan al viejo continente; por otro indagar acerca de la importancia de las comidas (Harris, 1992; Deveny, 2012 y Counihan y Van Esterik, 2008) en un corpus de películas españolas que tienen como tema principal la inmigración: Cosas que dejé en La Habana (1997) de Manuel Guttiérrez Aragón; Flores de otro mundo (1999) de Icíar Bollaín y El próximo Oriente (2006) de Fernando Colomo.

Palabras clave: Cine español, inmigración, comida, vida cotidiana.

In recent decades, immigration to the countries of southern Europe has become an everyday matter. In the case of Spain, recent studies indicate that the immigration flow has grown very rapidly, changing its tradition of issuing country to country receiving immigrants. This article has two objectives: first, to analyze how Spanish films depict the everyday life (Lefebvre, 1971; De Certeau, 1999; Perec, 1973 and Juan, 2008) of the immigrants who come to Europe; and second, to inquire about the importance of foods (Harris, 1992; Deveny, 2012 and Counihan and Van Esterik, 2008) in a corpus of Spanish films whose main topic is immigration: Cosas que dejé en La Habana (1997) by Manuel Guttierrez Aragon; Flores de otro mundo (1999) by Iciar Bollaín and EI próximo Oriente (2006) by Fernando Colomo.

Keywords: Spanish Cinema, immigration, foods, everyday life. 


\section{Introducción}

En los últimos 25 años la sociedad europea ha vivido un cambio trascendental debido a los enormes movimientos migratorios desde el norte de África, los países de América Latina y Europa del Este. Debido a su posición geográfica, países del sur de Europa se convierten en la puerta de acceso, una contact zones (Pratt, 1992: 7) hacia el viejo continente. Entre ellos se encuentra España, un territorio tradicionalmente de partida y no de llegada que, sin embargo, hacia fines de la década de 1970 y principios de los ochenta presencia un cambio trascendental, ya que esta situación se invierte, particularmente, por dos motivos: por un lado, el retorno de muchos emigrantes a su país de origen y, por otro lado, la llegada de inmigrantes extranjeros (Calavita, 2008: 4).

Durante las últimas décadas, la inmigración hacia los países del sur de Europa se ha convertido en una cuestión cotidiana. En el caso de España, estudios recientes señalan que el flujo inmigratorio ha crecido muy rápidamente, cambiando su tradición de país emisor a país de receptor de inmigrantes. Según el Instituto Nacional de Estadística (INE) el 2008 suma 599.074 recién llegados a España ${ }^{1}$ y según el Colectivo IOE, ${ }^{2}$ entre el 2001 y 2008 el promedio anual es de 575.000 personas, dato que deja a España "en el décimo país del mundo por número total de inmigrados" (2008: 1). ${ }^{3}$ Estos datos dan cuenta de grandes cambios, tanto económicos como sociales y culturales por los que atraviesa el tejido social español. En este caso es preciso destacar que con el paso del tiempo las cuestiones más candentes relacionadas con la inmigración se han reflejado en las diferentes formas de arte. Entre ellas el cine, que por sus particulares características culturales no solo evidencia estructuras y prácticas sociales, sino que también abre espacios de debate creando nuevas dinámicas o modificando las existentes. Los crítica concuerda que la nueva realidad social española es representada por el séptimo arte a partir de 1990, momento en que las películas acerca de inmigración comienzan a llegar a la pantalla grande en España4. Isabel

\footnotetext{
1 Disponible en red. [http://www.ine.es/jaxi/menu.do?type=pcaxis\&path=\%2Ft $20 \% 2 \mathrm{Fp} 2$ $77 \&$ file =inebase\&L=0]. Consultado el 19/08/2015.

2 Forman parte del Colectivo Ioé: Carlos Pereda, Walter Actis y Miguel Ángel de Prada, entre otros.

3 Para ampliar véase el análisis publicado por el Colectivo IOE con la colaboración de Graciela Malgesini, Ana I. Planet y Daniel Wagman (2008). "Dimensiones de la inmigración en España. Impactos y desafíos", en Inmigrantes, nuevos ciudadanos, FUNCAS, Madrid. En el que se sostiene que "a 1 de enero de 2008, España se ha convertido en el décimo país del mundo por número total de inmigrados, revirtiendo una larga tradición histórica que la caracterizaba como país de emigración" (en red www.colectivoioe.org).

4 Todos estos autores señalan la cinta Las cartas de Alou (1990) de Montxo Armendáriz como la primera película que tiene a un inmigrante como protagonista. Para Isabel Santaolalla, se trata de "la película [española] que inaugura el género de las narrativas de inmigración" (2005: 120), para Chema Castiello es en la que se evidencia "una mirada nueva, crítica y comprometida" (2005: 16) en relación con la nueva realidad española. Por su parte,
} 
Santaolalla sitúa el año 1996 como un punto de inflexión en que "la industria pareció por fin comenzar a asimilar los efectos de las políticas más integradoras [...] sobre el imaginario social y artístico español" (2005: 23); de hecho, durante ese período se estrenan seis títulos 5 que toman al inmigrante como punto central del relato.

Para reflexionar acerca de estas cuestiones, este artículo persigue un doble objetivo, por un lado analizar cómo el cine español representa la vida cotidiana de los inmigrantes que llegan al viejo continente, para ello se toman en consideración los aportes teóricos de Lefevbre (1971), De Certau (1999), Perec (1973) y Juan (2008); por otro lado y a partir de los estudios de Harris (1992), Deveny (2012) y Counihan y Van Esterik (2008) y, por otro, se indaga acerca de la importancia de las comidas en un conjunto de películas españolas que tienen como tema principal la inmigración. En su mayoría estas producciones abordan el tema desde una perspectiva bastante unilateral como el viaje a "la tierra prometida" o la llegada del inmigrado y su adaptación al nuevo ambiente, es el caso de Cosas que dejé en La Habana (1997) de Manuel Guttiérrez Aragón; Flores de otro mundo (1999) de Icíar Bollaín y El próximo Oriente (2006) de Fernando Colomo. En todas ellas se muestra cómo los recién llegados logran adaptarse a la nueva lengua e incluso a los diferentes tipos de trabajo que les toca en suerte. No sucede lo mismo, pues, con las comidas. Quizá porque existen siempre buenas razones para que la gente haga lo que hace, y la elección de un determinado tipo de comida no es una excepción, como señala Harris (1992: 4). Deveny afirma "[the] food is intrinsically tied to culture" (2012: 271), es por ello que en el grupo de películas aquí propuestas las diferencias culturales se manifiestan, sobre todo, durante la preparación de la comida y su presencia ocupa un lugar fundamental en la cotidianidad de sus protagonistas; aspectos que se convierten en puntos de conflicto tanto entre españoles y extranjeros como entre sujetos de una misma comunidad de origen, tal vez porque "los inmigrados siempre sienten nostalgia de las comidas de su tierra" (1987: 15), como señala Jean-Louis Flandrin.

\section{Un recorrido por la vida cotidiana}

Lo que hace que algo sea extraordinario es la idea de extrañamiento ${ }^{6}$ ante un determinado hecho o cuestión, por ello cuando hablamos de vida ordinaria no podemos dejar de lado su otra cara indisociable: la vida extraordinaria (Juan, 2008: 434-435). Un acontecimiento excepcional puede convertirse en uno habitual a partir de la repetición de este último y del mismo modo la no repetición de un acontecimiento ordinario lo transformaría en

Inmaculada Gordillo lo considera "el primer film de inmigrantes" (2006: 210); Barbara Zecchi sostiene que es "el primer largometraje español sobre la inmigración a España" (2010: 157) y Daniela Flesler afirma: "since 1990, Spanish cinema has produced a variety of stories centering on African and North African immigrants' live" (2008: 132).

5 Es el caso de las películas: Bwana (1996) de Imanol Uribe, Taxi (1996) de Carlos Saura, Susanna (1996) de Antonio Chavarría, Menos que Cero (1996) de Ernesto Tellería y La sal de la vida (1996) Eugenio Martín.

6 Para ampliar caerca de la idea de "extrañamiento" véase Heller, Agnès. Sociología de la vida cotidiana. Barcelona, Península, 1994. 
excepcional. Es decir, que este pasaje, de carácter dialéctico, puede mudar simultáneamente un hecho cotidiano en uno no cotidiano dependiendo, de los usos y costumbres que cada sociedad imponga. En otras palabras, lo ordinario y lo extraordinario son relaciones que se necesitan mutuamente para adquirir una entidad propia, pero no quita, que el estado de una -luego de un tiempo- puede convertirse en la otra.

En 1973 Georges Perec acuña el concepto de I'infra-ordinair (1973) con el que da cuenta de los aspectos mínimos de la vida cotidiana. El filósofo francés señala que las prácticas diarias nos llevan a detener la mirada en lo extraordinario dejando de lado lo habitual por ser conocido. Por medio de lo que llama proceso de desfamiliarización, Perec invita a observar los aspectos triviales de la vida cotidiana bajo una perspectiva diferente, la de lo acostumbrado. Asimismo, Agnes Heller da cuenta de lo cotidiano como lo "común, lo habitual, lo que hacemos todos los días, y por hacerlo todos los días no lo registramos verdaderamente" (1994: 67), Pierre Mayol, a su vez, conduce su mirada hacia los actos que pasan inadvertidos "para la conciencia de los sujetos, pero resultan decisivos para la identidad individual y de grupo" (1999: 7), Juan, por su parte, sostiene que lo cotidiano se reduce a "los gestos efímeros a través de los cuales pasa la vida" (2008: 432). Partiendo de estas consideraciones se puede decir que los cuatro autores coinciden en que la importancia de los actos diarios está justamente en las prácticas -incluso- banales de nuestra cotidianidad.

Guy Thuillier (citado por De Certeau), en relación con la vida cotidiana, advierte que "hay una vida y una muerte de las acciones" (1999: 208), por su parte, Schutz y Luckmann sostienen que "el mundo de la vida es, ante todo, el ámbito de la práctica de la acción" (1977: 38). Resulta evidente, entonces, que a pesar de postular aspectos en contraste, en estos autores se advierten también puntos de encuentro, por un lado coinciden en el que la acción no vive por sí misma, sino que necesita de un actor que la ejecute; por otro, comprenden lo cotidiano como el lugar fundamental de acción e intersección entre el individuo y la sociedad. Como estos roles son mutables, es lícito considerar que lo extraordinario se acerca más bien a la muerte de la acción (Thuillier) y lo ordinario a la existencia de la misma (Schutz y Luckmann). Si tomamos como válida esta proposición podemos decir que la acción solo tiene vida en tanto y en cuanto su utilidad así lo requiere. Es decir, que su permanencia dependerá de las reactualizaciones de los sujetos que la protagonizan y de su consenso ante tal o cual situación. Un aporte para reflexionar acerca de la vida cotidiana es $A$ Theory of Human Motivation (1943) de Abraham Maslow, quien toma como punto de partida el concepto de necesidad para establecer cinco jerarquías de necesidades humanas que agrupa en dos grandes bloques -las más objetivas y las más subjetivas-, ambas se suceden en una escala ascendente. En el primer grupo se reúnen las necesidades fisiológicas, de salud y seguridad, de pertenencia y amor, de estima. Un segundo bloque, que ha sido muy poco desarrollado por Maslow, lo componen las necesidades de autorrealización del sujeto; esta teoría, muy en boga después de la Segunda Guerra Mundial, con el pasar de los años cobra gran impacto para el marketing y la psicología social. Con un enfoque diametralmente opuesto, Agnès Heller publica Una revisión de la Teoría de 
las necesidades (1996), ensayo en el que sostiene que las necesidades "se refieren siempre a valores. Y son definibles solo a partir de valores" (1996: 56). La jerarquía de las necesidades propuesta por la principal exponente de la Escuela de Budapest se desarrolla en contraste con la teoría de Maslow deteniéndose en la superación de las jerarquías. Heller sostiene que cada contexto se supera por medio de la transformación de la sociedad y una vez en la nueva etapa se lograría satisfacer una necesidad plenamente. Otra de las diferencias entre ambos autores es que Maslow plantea su teoría a partir de la homogeneización de los necesidades del hombre. Heller, en cambio, sostiene que "en la vida cotidiana los tipos de actividad son tan heterogéneos como las habilidades" (1996: 95), es decir, que las aptitudes, los tipos de percepción y los afectos entre otros, son el resultado de la superación de las jerarquías.

\section{Vida cotidiana y comidas en el cine español}

El cine, en cuanto productor de imágenes en movimiento, da vida a la representación de las pequeñas acciones cotidianas y las transforma. De hecho, lo habitual de esas acciones al ser registradas y luego proyectadas adquieren un espacio nuevo, transformando lo ordinario en infraordinario (Perec) o, como prefiere llamarlo Heller, "lo cotidiano" en "no cotidiano". Sigmund Kracauer sostiene que "al registrar el mundo visible -trátese de la realidad cotidiana o de universos imaginarios-, las películas proporcionan claves de los procesos mentales ocultos" (1995: 15). Esta afirmación no resulta extraña si consideramos que las artes visuales generan discursos que otorgan significaciones a las prácticas cotidianas, produciendo y reproduciendo un conjunto de actividades.

En De Caligari a Hitler (1960), Kracauer remite a una experiencia personal "el cine como descubrimiento de las maravillas de la vida cotidiana" (1995: 5), para dar cuenta de su "impresión embriagadora" al ver por primera vez una película. En esta afirmación el crítico alemán hace hincapié en "la captación del momento mágico de la verosimilitud de lo cotidiano" (1995: 5), que más adelante define como the flow of life, entendiendo con ello la composición del lenguaje audiovisual en tanto sistema de representaciones de la realidad que nos rodea. Por ello, no es arbitrario decir que el nacimiento del cine está íntimamente relacionado con la representación de la vida cotidiana. De hecho, es suficiente pensar en La llegada del tren o en La salida de los obreros de una fábrica, de los hermanos Lumiére, para darse cuenta de cuán implicada está la representación de la vida cotidiana en el cine. En esta dirección, podría decirse que trozos de vida cotidiana como un tren que pasa u obreros que salen de su lugar de trabajo devienen relatos trascendentales al ser filmados y proyectados por primera vez en una pantalla grande, transformándose luego en partes fundacionales de la Historia del cine.

Deveny afirma "[the] food is intrinsically tied to culture" (2012: 271), es por ello que en el grupo de películas aquí propuestas las diferencias culturales se manifiestan, sobre todo, durante la preparación de la comida y su consumo; de hecho su presencia ocupa un lugar primordial en la cotidianidad de sus protagonistas. La comida "pasa desapercibida por demasiado evidente, [...]", 
dice Bou (2013: 146), pero en este grupo de películas españolas constituye lo cotidiano y, lejos del simple acto de prepararla y servirla, se convierte en una práctica en que se plantean tensiones entre tradiciones gastronómicas diferentes pero también entre integrantes de un mismo grupo de origen, causando conflictos.

La película Cosas que dejé en La Habana es un claro ejemplo de lo apenas expuesto. Estructurada desde dos ejes narrativos, el primero se desarrolla a partir de la adaptación a la vida cotidiana española de tres hermanas cubanas que Ilegan a Madrid y que se hospedan en casa de tía María. El segundo eje muestra la vida de Igor, un buscavidas que se vale de la reafirmación de su imagen estereotipada de cubano exótico (Shohat et Stam 1994: 196-197), para seducir españolas adineradas y sacar provecho de ellas por un lado, y "ayudar" a los recién llegados a legalizar su situación consiguiéndoles pasaportes falsos, por otro. La película muestra a los protagonistas que, sin cruzarse, comparten el mismo espacio: el aeropuerto de Barajas al que llegan Nena y sus dos hermanas y una familia cubana que se encuentra en tránsito hacia los Estados Unidos a la que va a recoger Igor. Rápidamente surgen los conflictos, quien debe entregar los papeles a esa familia no se encuentra en el aeropuerto y eso hace que Igor los "hospede" en la habitación que alquila en una vieja casona habitada por inmigrantes. Las tres hermanas no logran encajar con tía María que no habla, no come y no se viste como una cubana, sino más bien como una señora europea. Si en un primer momento las jóvenes se sienten fascinadas por los modales de tía María, muy pronto descubren la otra cara de la moneda: es decir, la negación hacia lo cubano y los "planes" que tiene para cada una de ellas.

Casi como en una ceremonia de comensalidad, "cuya función primordial es estrechar las relaciones de los miembros del grupo" (Maury Sintjago, 2010: s.p.), las cuatro mujeres de Cosas que dejé en La Habana se reúnen frente a la mesa y llevan adelante un rito de modo intimista que está lejos de la tranquilidad esperada, ya que en más de una ocasión el sentarse a comer resulta un momento de conflicto. Durante la primera comida tía María da una pequeña lección de cómo un recién llegado debe comportarse ante la comida en un país extranjero: -"Lo primero que hay que educar cuando se llega a otro país es el paladar, aquí no se come todo junto como allá. No señor. Aquí se sirve un primer plato, un segundo plato y a veces un tercer plato"-. Es importante notar que a la primera comida también participa Lola, la vecina española que vive en el piso de arriba, pero el conflicto no se da con ella (es decir con la española), sino entre las jóvenes cubanas recién llegadas y tía María que hace más de veinte años vive en España y quiere que las sobrinas incorporen desde su llegada el gusto de la comida española. La observación constante de tía María acerca de lo que Nena, Rosa y Ludmila dicen, hacen y comen las acercan a "the type of immigrant who tries to totally incorporate herself into the new culture, leaving her own culture behind" (Deveny 82). Dicho de otro modo, tía María ya no representa a la mujer cubana sino a una distinguida mujer europea y, por cierto, su actitud provoca varios momentos de conflicto durante el film. Es evidente que la cotidianidad de las jóvenes cubanas asume un cambio radical, y que la nueva realidad las pone frente a conflicto con el Otro y sus costumbres. 




Escena en que se discuten los detalles del acuerdo prematrimonial

Cosas que dejé en La Habana

Es también durante una comida que se discuten los detalles de un acuerdo prematrimonial, de una falsa boda entre el español Javier y la cubana Rosa, a quien tía María presenta como - "una chica muy buena y muy pacífica, como ya no se ven en España [...], la más habituada al sacrifico"Asimismo, hay dos escenas que resultan fundamentales para describir el choque cultural entre las recién llegadas y tía María, quien apenas prueba la comida preparada por Rosa pregunta -"¿y esto qué es?", -"quise darle un toque cubano"-, responde Rosa. Pero tía María se enfada y la amonesta diciéndole que a ella no le agrada la mezcla, sino -"los sabores netos: el cocido en Madrid y el ajiaco en Cuba"-. Sentencia que se contradice cuando de noche entra en la cocina para tomar un vaso de agua, allí el olor de la comida cubana le resulta irresistible, de modo que en pijamas y despeinada (casi como si fuese otra), primero calienta la olla y luego se lanza a comer "las sobras del ajiaco" (Rodríguez Fernández, 2007: 23), sin siquiera utilizar un plato. Esta escena es un claro ejemplo de la negación de la cultura de origen delante de sus sobrinas, "especially dishes from the homeland" (Deveny, 2012: 113), pero muestra también la necesidad velada de esos sabores, que a escondidas es develada.

Flores de otro mundo relata las historias de Patricia, Milany y Marirrosi, tres mujeres que llegan al perdido pueblecito de Santa Eulalia -nombre ficticio del pueblo de Cantalojas, situado entre las provincias de Soria y Guadalajara- en busca de una vida mejor. Patricia es una mujer dominicana que vive en España desde hace cuatro años y tiene como objetivo regularizar su situación de ilegalidad para así traer a España a sus dos pequeños hijos. En Santa Eulalia conoce a Damián, un hombre tímido y sumiso que 
vive bajo las órdenes de su madre. Milany es una joven cubana con ansias de libertad que acaba de llegar a España de la mano de Carmelo, un hombre muy adinerado que tiene unos veinte años más que ella y que cansado del turismo sexual en Cuba decide "traerse a su cubanita" al pueblo. Por último Marirossi, una mujer española de mediana edad que comienza una relación con Alfonso, un agricultor de Santa Eulalia.

Flores de otro mundo plantea en más de una ocasión el conflicto entre Patricia y Gregoria, la madre de Damián, quien nunca ha aceptado la unión de su hijo con la joven caribeña. A lo largo del film Gregoria acusa a Patricia de haber usurpado su lugar en la casa, sobre todo en la compra cotidiana y la preparación de la comida. Lo que está en disputa entre estas mujeres no es solo el "sujeto" (Damián) que es objeto de amor para ambas, sino y sobre todo el lugar que la cocina ocupa en esa casa; convirtiéndola en un espacio físico de conflicto.
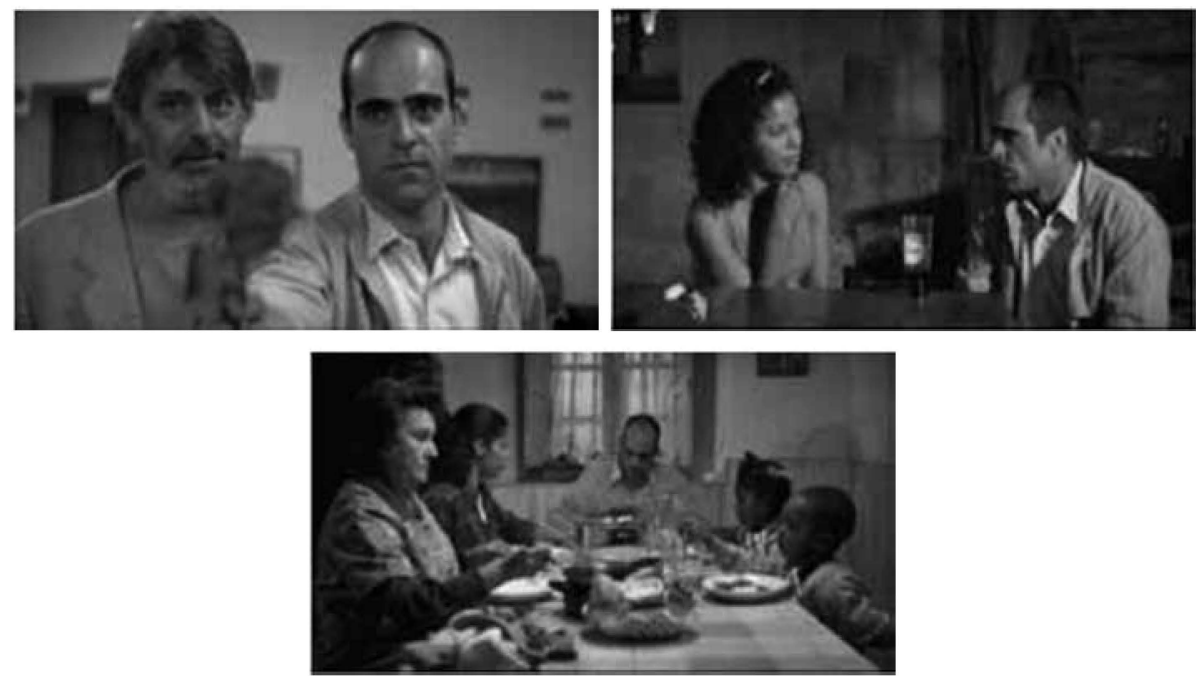

Encuentro, propuesta y cena. Tensión en torno a la mesa

Flores de otro mundo

De Certeau afirma que "muchas comidas familiares son el teatro de una lucha encarnizada por el poder" (1999: 195), si bien en este caso el filósofo francés se refiere a la relación entre padres e hijos, bien puede servir para dar cuenta de la lucha de las dos mujeres que, con el afán de que Damián las reconozca como "señoras de la casa", mantienen un enfrentamiento constante en el que la cocina se convierte en una suerte de espacio de control sobre los que habitan la casa. Valga de ejemplo, pues, la escena en que Patricia, con el intento de conservar su origen y el de sus hijos, prepara una comida que no es del agrado de Gregoria, quien para dar cuenta de su desconformidad le dice -"desde que el mundo es mundo las judías se cocinan con caldo"-. La frase pronunciada por Gregoria tiene un doble significado, por un lado dejar en claro cómo se cocina en esa casa y, por otro, reafirmar su lugar en la cocina (y por extensión en la casa), evidenciando no solo que Gregoria 
no acepta a Patricia, sino y sobre todo "lo que culturalmente representa" (Rodríguez Fernández, 2007: 19).

La llegada al pueblo desde Madrid de las amigas de Patricia es una secuencia muy bien analizada por Rodríguez Fernández (2007), quien propone un esquema en tres partes para dar cuenta de la función que estas visitas representan, así la entrada, la preparación de la comida y la cena que comparten junto a Damián, Gregoria y los hijos de Patricia. Me interesa detenerme en la segunda de ellas. La escena se abre con un plano general que muestra a Patricia y sus amigas en la cocina de la casa (espacio vital y por excelencia de Gregoria) preparando alegremente la comida. Un primer plano toma un bol con plátanos listos para ser cocinados, mientras las cuatros mujeres se mueven al ritmo de música caribeña, pero el clima de fiesta se interrumpe con la llegada de Gregoria, quien no responde al saludo de las amigas de Patricia y solo dirigiéndose a ella dice: -"la próxima vez que vaya a venir gente, me avisas"-, y se marcha sin posibilidad de réplica. Esta escena denota la desaprobación de Gregoria y "el rechazo absoluto hacia estas mujeres y su cultura" (Rodríguez Fernández, 2007: 19). Lo mismo sucederá con la comida que preparan las dominicanas, que en lugar de ser "un brindis por las relaciones interculturales" (20), el silencio imperante la transforma en otro motivo de desencuentro cultural en torno a la mesa.

Hacia el final la historia de Patricia y Damián se convierte en "una metáfora de la posibilidad de integración de los inmigrantes en el país" (Villar-Hernández, 2002: 6), ya que al asumir que puede perder al hijo, Gregoria decide ceder "su espacio vital", es decir, su cocina, a Patricia. Esto se verá en la escena final cuando la abuela está en el salón abriendo los regalos de Navidad con los nietos y Patricia está sentada compartiendo la cena con los demás parientes de su marido, esto evidencia que la joven caribeña ha logrado un espacio no solo en la casa sino también dentro de la pequeña sociedad de Santa Eulalia.

Ambientada en el bullicioso barrio madrileño de Lavapiés, El próximo Oriente es una comedia romántica de enredos que gira en torno a la multiculturalidad. Protagonizada por dos hermanos Caín, un joven simpático y tímido que trabaja en una carnicería del barrio y vive bajo la sombra de su hermano Abel, un chico guapo y seductor que está casado, tiene dos hijas y trabaja en un banco. Cuando Abel se entera de haber dejado embarazada a Aisha, una atractiva vecina bangladesí, decide mudarse a Mallorca con su mujer y su hija. La desesperación a causa del abandono lleva a Aisha a intentar quitarse la vida. Por error la familia de la joven cree que el padre del niño es Caín. Aisha y Caín deciden poner en marcha un boda falsa y para ello es necesario que el joven español se convierta al Islam. Si bien la película retrata situaciones en las que la diversidad cultural provoca puntos de conflicto, se desarrolla con un gran toque de buenismo (Bou, 2013: 146), valgan de ejemplo las escenas en las que los españoles Caín y Milagros superan las diferencias religiosas, por ejemplo. La historia se cierra con un anunciado happy ending que la convierte en una especie de "canto a la interculturalidad", en la que el amor y la aceptación resultan los ingredientes fundamentales del film. 
De Certau comenta que "la preparación culinaria impone una serie coercitiva al interno de la cual los elementos ya no son permutables" (1999: 87 ), es decir que una vez elaborada la comida se servirá en un cierto orden y no en otro, ya que eso comportaría un desorden, una "especie de obscenidad". Esta aparente banalidad da lugar a conflictos en Cosas que dejé en La Habana, Flores de otro mundo y El próximo Oriente. En la primera, Nena, la menor de las hermanas, aprovecha la distracción de tía María durante la comida y toma una uva, pero rápidamente es amonestada por esta que sentencia: -"Las frutas se comen al final aquí"-. Las disculpas de Nena no tardan en llegar y evidencian, con cierta vergüenza, que la ha ganado la tentación, ya que es muy difícil encontrar uvas en Cuba. Lo que me interesa de la afirmación de tía María es la idea de lo que se debe hacer "aquí" (España), en evidente contraste con lo que se hace "allí" (Cuba). A diferencia de tía María, las jóvenes cubanas responden al tipo de inmigrantes que no renuncian a sus raíces e incluso es desde allí que intentan insertarse y adaptarse a la vida cotidiana española. En la dirección opuesta se encuentra la actitud de tía María, que para ser parte de la sociedad renuncia a "su idiosincrasia, intentando identificarse con la cultura del país de acogida" (Rodríguez Fernández, 2008: 17), evidenciando que las prácticas cotidianas de "allí" no deben ser conservadas "aquí". Al igual que el personaje de Patricia en Flores de otro mundo, las tres hermanas de Cosas que dejé en La Habana se recrean preparando las delicias gastronómicas de su tierra, idea que ha sido leída por Rodríguez Fernández como una política de resistencia que tiene como fin último evitar una nueva colonización (2007: 22), ya que su lugar de origen no deja de tener espacio en su cotidianidad y de hecho es al que recurren mediante la preparación y degustación de sus comidas típicas.



La adaptación e integración de Caín

El Próximo Oriente 
Diferente es lo que sucede en El próximo Oriente. Caín, el español, es quien se adapta a la cultura y costumbres de su nueva familia. Si, en principio, la idea de convertirse al Islam es una mera apariencia, de hecho en una de las primeras escenas no solo no le interesan las prácticas que prevé el Ramadán, sino que también se lo ve frente a la tv comiendo jamón y tomando cerveza; en la siguiente ocasión se lo muestra levantándose al alba y rezando al igual que su suegro. Caín cambia su religión, su trabajo y comienza a ocuparse del restaurante de su nueva familia, ayudándoles tanto con un préstamo bancario -que obtiene sin dificultades gracias a su condición de español- como con la transformación del local que se convierte de "muy tradicional y poco atractivo en un bar de música moderna" (Bou, 2013: 147), en el que las jóvenes blangadesíes tienen una activa participación. Si por un lado estas escenas dan cuenta de la aceptación de la cultura foránea por parte de Caín, por otro lado muestra cómo las segundas generaciones también están abiertas al cambio.

En un breve e interesante artículo titulado "Toward a Psycociology of Contemporary Food Consumation",7 Roland Barthes explora los aspectos y las significaciones culturales de la nutrición contemporánea y, ante la pregunta ¿qué es la comida?, el filósofo francés sostiene que es "al mismo tiempo un sistema de comunicación, un cuerpo de imágenes, un protocolo de usos, de situaciones y de conductas" (2013: 25). Esta afirmación encaja muy bien con lo que representa la comida en El próximo Oriente y establece marcadas diferencias con las películas Cosas que dejé en La Habana y Flores de otro mundo. En estas últimas todo lo que ocurre en torno a la mesa es motivo de conflicto, en cambio, en el film de Colomo la comida establece los límites que Caín debe superar para lograr la armonía, tanto familiar como personal. Por ello no resulta antojadizo que sea justamente en torno a la mesa que Caín intente comunicarle a su suegro acerca de los cambios producidos en el bar, entre otros la venta de bebidas alcohólicas, la introducción de la música en vivo y la participación activa de sus hijas en el local. Caín elige formar parte activa de su nueva familia y para ello decide cambiar sus hábitos alimentarios y eso lo lleva a cambiar su modo de vida, ya que "este alimento resume y transmite una situación, constituye una información, es significativo" (14).

Hacia el final y luego de una profunda crisis, Caín duda entre matar a Abel o quitarse la vida. Decide volver a su casa y enfrentar a su hermano con un hueso de cerdo que recoge de la calle -que como en el mito bíblico- toma la función de un arma. Entra en la casa con el hueso en la mano pero al escuchar el llanto del bebé arroja el "arma" al suelo y calma al niño, "consolidating in this way his identification with his self invented image as father and husband" (Martín, 2010: 195), de este modo restablece el orden del film, en el que triunfa el amor, la tolerancia y la integración. Sirvan también de ejemplo la unión entre Milagros y Cristóbal.

\footnotetext{
7 Originalmente publicado en Barthes, Roland (1961), "Toward a Psycociology of Contemporary Food Consumation", Annales, Economies, Sociétés Civilisations 5 (Sep-Oct), pp. 977-986. Publicado en español en Torres Salmerón, Lucía et Alonso, Luis Enrique (trad.). Empiria. Revista de Metodología de Ciencias Sociales 11 (enero-junio), 2006, pp. 205-221.
} 


\section{Reflexiones finales}

Para Henri Lefebvre los "materiales" que constituyen la vida cotidiana son el trabajo, el ocio, la sexualidad, el transporte, la residencia y la comida entre otros (1972); en una misma dirección Michel Maffesoli advierte acerca de la importancia de los modos de vida, la comida y el uso de las vestimentas en nuestras megalópolis (2000: 26), prácticas fundamentales que organizan la manera de vivir. Al ser "la alimentación la primera de las necesidades" (Barthes, 2013: 26), no resulta casual que la cotidianidad de los españoles advierta las transformaciones de las costumbres alimentarias introducidas por los recién llegados. De hecho, en cada uno de los filmes aquí propuestos se encara desde una mirada diferente los cambios en la vida cotidiana de sus protagonistas que, como se ha querido demostrar, en la mayor parte de los casos está asociada con las costumbres alimentarias.

El personaje de tía María, en Cosas que dejé en La Habana, representa a una inmigrante cubana que ha asimilado la cultura de llegada y reniega de sus orígenes, y es este uno de los mayores conflictos que se plantea a la largo del film que, como se ha visto, se manifiesta en torno a la mesa o durante la preparación de la comida. Por su parte Gregoria, la suegra de Patricia, en Flores de otro mundo, es la voz de la España conservadora y poco abierta a la integración. El conflicto entre estas dos mujeres tiene lugar en la cocina, ya que el cómo se "debe" cocinar un cierto alimento es siempre motivo de pugna entre ellas, es decir, que la cocina se convierte en un espacio de lucha entre culturas. A diferencia de lo que sucede en las películas apenas citadas, Caín, en El próximo Oriente, es el español que está rodeado de inmigrantes, es decir, la voz de la España abierta a la integración (Martín, 2010: 195), y esto lo lleva a ganarse el amor de Aisha y el afecto y el respeto de su nueva familia. Aquí más que rituales de comensalidad encontramos un film que en tono de comedia muestra la evolución de dos personajes que se unen casi por error, pero que deciden transitar el camino mediante la comida, que al decir de Barthes "sirve de signo entre los participantes de una población dada" (2013: 16).

Es importante señalar que en todos estos filmes se plantean los cambios que atraviesa la cotidianidad de sus protagonistas a partir de su adaptación al nuevo ambiente y con ello a las costumbres alimentarias. La vida cotidiana es el connective tissue de todos los pensamientos y las actividades humanas (Lefebvre, 1967: 298), es también el "lugar fundamental de intersección entre el individuo y la sociedad" (Wolf, 2006: 6), es la rutina diaria que no observamos en cuanto banal, en cuanto conocida. Dicho de otro modo, lo cotidiano es lo no excepcional, lo que ocurre cada día y por resultar acostumbrado no lo observamos.

\section{Obras citadas}

Alsina, Miquel Rodrigo (1999). La comunicación intercultural. Barcelona, Antrophos Editorial.

Barthes, Roland (2013). "Toward a Psycociology of Contemporary Food Consumation". En Counihan, Carole et Van Esterik, Penny. Food and Cultures: A Reader. New York, Routledge, pp. 23-30. 
Bou, Enric (2013). "Billetes sin retorno. Inmigración y vida cotidiana en el cine español", en Júlia Almeida, Paula Siega, Literatura e voz subalternaANAIS Estudos culturais e pós-coloniais: literatura e voz subalterna. Vitória ES, GM Grafica e Editor, pp. 139-152.

Colectivo IOE (2008). Inmigrantes, nuevos ciudadanos. Madrid, Funcas.

De Certeau, Michel (1999). La invención de lo cotidiano II. Habitar, cocinar. México, Universidad Iberoamericana.

Deveny, Thomas (2012). Migration in Contemporary Hispanic Cinema. Maryland, Scarecrow Press.

Flandrin, Jean Louis (1987). "Historia de la alimentación: Por una ampliación de las perspectivas". Manuscrits. Revista d'historia moderna 6, pp. 7-30.

Harris, Thomas (1992). Buono da mangiare. Enigmi del gusto e consuetidini alimentari. Torino, Einaudi Tascabili.

Heller, Ágnes (1994). Sociología de la vida cotidiana. Barcelona, Península. (1996). Una revisión de la teoría de las necesidades. Paidós, Barcelona.

Instituto Nacional de Estadística (INE). Estadística de Migraciones. Disponible en red. [http://www.ine.es/jaxi/menu.do?type=pcaxis\&path=\%2Ft20\%2 Fp277\&file $=$ inebase $\& L=0]$.

Juan, Salvador (2008). "Un enfoque socioantropológico sobre la vida cotidiana: automatismos, rutinas y elecciones". Espacio Abierto 17.3, pp. 431-454.

Kracauer, Siegfried (1996). Teoría del cine: la redención de la realidad física, Buenos Aires, Paidós. (1995). De Caligari a Hitler: una historia psicológica del cine alemán. Buenos Aires, Paidós.

Knudson-Vilaseca, Emily Ann (2007). Embodying the Un/home: African Immigration to Portugal and Spain. Minnesota, ProQuest.

Lefebvre, Henri (1972). La vida cotidiana en el mundo moderno. Alianza, Madrid.

Maffesoli, Michel (2000). "Sociedad y naturalidad o la ecologización de lo social". En Lindón Villora, Alicia. La vida cotidiana y su espacio-temporalidad. México, Antrophos, pp. 19-44.

Martín, Sandra Stickle (2010). Moroccan Women and Immigration in Spanish Narrative and Film (1995-2008). University of Kentucky Doctoral Dissertations. En red [http://uknowledge.uky.edu/gradschool_diss/766]. Consultado el 17/05/2015.

Maslow, Abraham (1997). Motivación y personalidad. Madrid, Díaz de Santos.

Maury Sintjago, Eduard Antonio (2010). "Ritos de comensalidad y espacialidad. Un análisis antropo-semiótico de la alimentación". En red [http://www.ugr.es/\%7Epwlac/G26_45Eduard_Maury_Sintjago.html]. Consultado el 15/05/2015.

Mayol, Pierre (1999). "Habitar". En De Certeau, Michel. La invención de Io cotidiano II. Habitar, cocinar. México,Universidad Iberoamericana, pp. 3-12.

Perec, Georges. L'infra-ordinaire. Paris, Seuil, 1989.

Rodríguez Fernández, María del Carmen (2007). "Subjetividad postcolonial a través de los recuerdos de la madre tierra: las islas del Caribe como ejemplo". Letras Hispanas 4.2, pp. 16-25.

Santaolalla, Isabel. Los "Otros". Etnicidad y raza en el cine español contemporáneo. Zaragoza, Prensas Universitarias, 2005. 
Schütz, Alfred et Luckmann, Thomas (1977). La estructura del mundo de la vida. Buenos Aires, Amorrortu.

Shohat, Ella y Stam, Robert (1994). Multiculturalismo, cine y medios de Comunicación. Barcelona, Paidós Ibérica.

Villar-Hernández, Paz (2002). "El Otro: conflictos de identidad en el cine español contemporáneo". Graduate Romanic Association 6. En red [http://ccat.sas.upenn.edu/romance/gra/WPs2002/paz_1.htm]. Consultado el 03/05/2015.

Wolf, Mauro (2006). Sociologías de la vida cotidiana. Madrid, Cátedra.

\section{Filmografía}

Colomo, F. El Próximo Oriente. Sogecine/Colomo Producciones. España, 2006. Gutiérrez Aragón, M. Cosas que dejé en La Habana. Sogetel/Tornasol Films S.A. España, 1997.

Bollaín, I. Flores de otro mundo. La Iguana Films/Alta Films S.A. España. 1999. 